\title{
Desenvolvimento e uso de um software de gestão sob a ótica das dimensões organizacional, tecnológica e humana em empresas públicas
}

\begin{abstract}
RESUMO
O presente trabalho aborda o uso de sistemas de informação na administração pública, especificamente na Secretaria de Assistência Social, onde foi desenvolvido o software GESUAS como sistema de apoio à gestão. O objetivo proposto foi compreender o processo de implantação do GESUAS na Secretaria de Assistência Social no município de Viçosa, identificando as demandas de origem e como as dimensões organizacionais, tecnológicas e humanas influenciaram esse processo. Para isso, foram entrevistados o técnico responsável pelo sistema e funcionários da Secretaria de Assistência Social de Viçosa, utilizando-se da análise de conteúdo para tratar os dados coletados. Após realização das entrevistas, foram criadas categorias de análise para facilitar a compreensão do impacto do GESUAS naquele órgão. Notou-se que o uso do sistema trouxe implicações positivas tanto em aspectos organizacionais, quanto tecnológicos e humanos. A partir desde ponto é possível notar a importância do uso de tecnologia e sistemas de informação nas organizações públicas e, em contrapartida, as dificuldades desse processo, embora os resultados aqui obtidos não possam ser generalizados para outros casos.
\end{abstract}

Palavras-chave: Tecnologia da informação. Sistemas de Informação. Administração Pública. 


\section{INTRODUÇÃO}

As mudanças no mundo globalizado ocorrem rapidamente, impactando na disponibilidade e quantidade de informações, o que força a sociedade e as organizações a se reorganizarem constantemente (SANTOS JÚNIOR; FREITAS; LUCIANO, 2005). Laudon e Laudon (2010) comungam desta afirmativa, e acrescentam que a globalização trouxe uma série de desafios e oportunidades. As empresas, por exemplo, precisam ser e se manterem competitivas, uma vez que suas concorrentes não estão apenas na "vizinhança", e sim espalhadas ao redor do mundo, tornando possível a compra de um produto de outro país sem sair de casa por meio da internet, evidenciando a expansão de um mercado globalizado.

Neste cenário, o uso da tecnologia e de sistemas de informação de apoio a gestão tem sido fundamental para as organizações no sentido de auxiliá-las no cumprimento de seus objetivos. De acordo com Laudon e Laudon (2010) existem seis objetivos principais: a excelência operacional, o desenvolvimento de novos produtos, serviços e modelos de negócio, o estreitamento no relacionamento com os clientes e fornecedores, a melhor tomada de decisões, a conquista da vantagem competitiva e, por fim, a própria sobrevivência, ligada de maneira intrínseca com os demais.

Exemplos de sucesso e fracasso sobre o tema são numerosos. Stair e Reynolds (2006), citam o uso do software Microcat, desenvolvido pela empresa australiana Infomedia, para empresas automobilísticas como General Motors, Hyundai, Ford, Toyota, dentre outras. Este sistema cataloga componentes eletrônicos de veículos, facilitando a compra e venda dos mesmos, o que beneficia fornecedores e compradores. O uso do Microcat objetiva reduzir custos com erros e imprecisões nas transações comerciais entre as empresas, diminuir o tempo em que os fabricantes de automóveis demorariam para efetuar suas compras, além de aumentar o conhecimento dos fornecedores em relação ao seu mercado para otimizar produção e produtos. Por outro lado, a fabricante norte-americana de vestuário esportivo Nike passou por problemas ao tentar implantar um sistema ERP (enterprise resource planning) para o monitoramento em tempo real de suas atividades. Os pedidos de calçados foram feitos em duplicidade ou simplesmente não constaram no sistema, acarretando em um prejuízo de 100 milhões de dólares e na briga da Nike com a fabricante do software i2 Technologies, responsável pelo desenvolvimento do ERP (STAIR; REYNOLDS, 2006).

A implantação de um sistema de informação é considerada um fator crítico para as empresas, uma vez que esse processo envolve fatores organizacionais, humanos e tecnológicos (LAUDON; LAUDON, 2010). Desta forma, a cultura e a política organizacional voltada para inovação (fatores organizacionais), o treinamento e aceitação dos usuários do sistema (fatores humanos) e as novas tecnologias de hardware, software e de comunicação (fatores tecnológicos) devem ser levados em consideração para a implantação de sistemas de informação. No entanto, Mattos (2005), lembra que a maioria dos projetos são abandonados ou refeitos, demonstrando a dificuldade de se implantar um sistema enquanto a empresa realiza suas atividades. Além disso, algumas organizações necessitam de uma atualização contínua de seus sistemas, como as fabricantes de antivírus.

Embora estejam num ambiente mais estável quando se comparado ao setor privado, as organizações públicas também enfrentam barreiras e desafios para a implantação de sistemas de informação. As dificuldades estão relacionadas principalmente à burocracia necessária para o funcionamento dos mesmos, e também à falta de competitividade no setor, uma vez que os serviços ofertados não contam com a concorrência direta na maioria das vezes. Neste sentido, Stair e Reynolds (2006) citam o caso do estado de Illinois, nos Estados Unidos. Os estados e municípios americanos competem entre si na modernização de seus sistemas de informação. Illinois por sua vez ocupava o posto de $49^{\circ}$ e depois de investimentos da ordem de 2 bilhões de dólares na área, passou para a segunda posição. Foram contemplados sistemas na área de educação e pesquisas avançadas, saúde, biotecnologia e tecnologia da informação de ponta. Com o número de dados levantados pelos implantados, o governo pode fazer o uso dessas informações para gerir de maneira mais eficiente e eficaz seus recursos, impactando em benefícios para a população e funcionários públicos.

O uso de sistemas de informação por parte dos governos em seus processos é chamado de governo eletrônico ou e-gov. Este conceito aborda desde aspectos relacionados ao uso de tecnologia para a automação de serviços de escritório, como planilhas eletrônicas, até a integração entre as esferas federais, estaduais e municipais (SILVA; RIBEIRO; RODRIGUES, 2004). Existem quatro estágios do e-gov. O primeiro diz respeito à automação de escritórios, uso de planilhas eletrônicas etc., enquanto o segundo utiliza-se da internet para a realização de transações. Já o terceiro busca integrar as esferas dos governos e, por fim, o quarto estágio do e-gov, que foi alcançado por poucos países, como Reino Unido, e compreende o uso das informações geradas para melhorar a inteligência dos governos (SILVA; RIBEIRO; RODRIGUES, 2004). O Brasil não se encontra no último estágio, embora tenha se esforçado neste sentido (SIQUEIRA NETO; MENEZES, 2013). O uso de softwares 
na administração pública brasileira tem buscado trazer maior eficiência e eficácia para as organizações públicas, como o Sistema de Informação de Custos (SIC) do Governo Federal, que almeja melhorar a qualidade do gasto do governo (MONTEIRO et al, 2011).

Em todos os âmbitos da Administração Pública os sistemas de informação são essenciais. Para as políticas sociais e assistenciais os sistemas também garantem agilidade, confiabilidade e qualidade de informações. Nesse ínterim, foram criados dois softwares para auxiliar a tomada de decisão e levantamento de informações no âmbito da assistência social, chamados de GECRAS e GECREAS. Ambos foram desenvolvidos para atender a demanda da cidade de Viçosa, Minas Gerais, devido à instalação dos equipamentos do CRAS e CREAS na mesma.

Posteriormente, os programas foram unificados em um único sistema, que recebeu o nome de GESUAS. Em síntese, ele organiza os dados dos beneficiários de programas sociais, sejam indivíduos ou famílias, demandados pelos equipamentos municipais do Sistema Único de Assistência Social (SUAS). Outras funcionalidades importantes são a emissão de relatórios obrigatórios do Ministério do Desenvolvimento Social e Combate à Fome (MDS) e a geração de gráficos e tabelas com informações atualizadas, dando suporte ao gestor responsável em atividades e projetos. Ressalta-se que o mesmo tem a assinatura feita por várias cidades, salvo Viçosa, onde se originou a ideia e se desenvolveu a base de sua criação. Procura-se com essa pesquisa compreender e analisar a implantação do sistema de gestão para a Assistência Social do município de Viçosa, ressaltando as demandas de criação do sistema e suas funcionalidades frente as dimensões Humanas, Tecnológicas e Organizacionais que permeiam o processo.

A pesquisa se justifica pela importância do próprio SUAS e de seus serviços prestados aos cidadãos em situação de vulnerabilidade social. Melhorias na qualidade dos serviços e rapidez no diagnóstico dos problemas sociais de determinada localidade podem beneficiar a população como um todo. Por outro lado, a compressão da implantação de sistemas de informação na administração pública é outro fator importante, e, ao mesmo tempo, carente na literatura brasileira.

\subsection{Objetivo geral}

Neste sentido, o presente trabalho tem por objetivo principal compreender como se deu a tentativa de implantação do GESUAS na Secretaria de Assistência Social de Viçosa, identificando as demandas de origem e como as dimensões organizacionais, tecnológicas e humanas influenciaram esse processo.

\subsection{Objetivos específicos}

Responderá também aos seguintes objetivos específicos:

- Apresentar o GESUAS, bem como as demandas que o originaram;

- Descrever o processo de implantação do GESUAS;

- Analisar como as dimensões organizacionais, tecnológicas e humanas influenciaram o processo de implantação do GESUAS na cidade de Viçosa.

\section{TECNOLOGIA DA INFORMAÇÃO}

De acordo com Keen (1993 apud LAURINDO et al, 2001, p.160) o conceito de tecnologia da informação "é mais abrangente do que os de processamento de dados, sistemas de informação e engenharia de software, informática ou o conjunto de hardware e software, pois envolvem aspectos humanos, administrativos e organizacionais". Por sua vez, Silva, Ribeiro e Rodrigues (2004, p. 81) conceituam a tecnologia da informação como o "somatório de toda a infraestrutura tecnológica requerida para suporte aos sistemas de informação baseados em computadores". Ou seja, os sistemas de informação incluem no processo uma estrutura de hardwares e softwares. Os primeiros são a parte física dos sistemas, como computadores servidores, redes e periféricos. Já os segundos são os programas, sistemas operacionais e as plataformas de desenvolvimento e processamento dos sistemas de informação (SILVA; RIBEIRO; RODRIGUES, 2004).

Laurindo (2008) ainda acrescenta outros componentes à infraestrutura de tecnologia da informação além de hardware e software. A Figura 1 corrobora com tal visão. 
Figura 1 - Componentes da Infraestrutura de Tecnologia da Informação

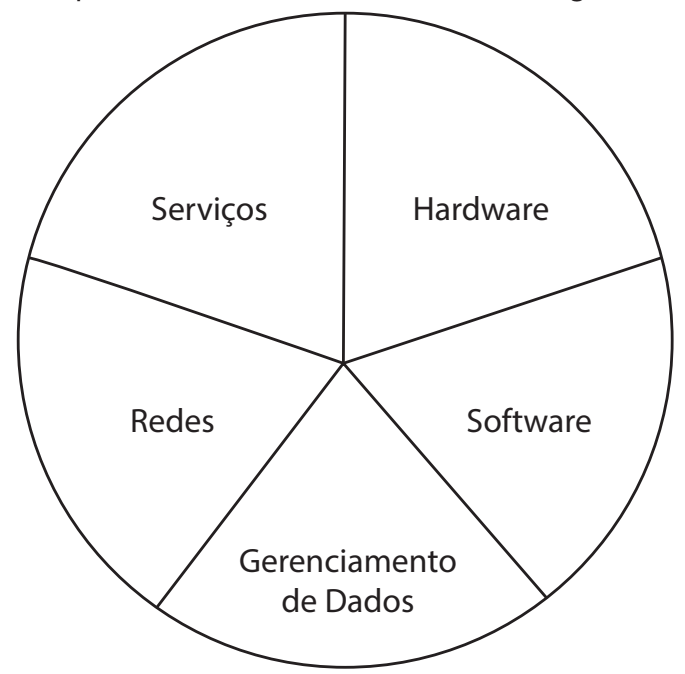

Fonte: Laudon e Laudon (2010, p. 105)

Para Laudon e Laudon (2010), o gerenciamento de dados vai além da própria mídia física, englobando também algum software de gestão de dados para organizar, gerenciar e processar os dados da organização, como estoques e fornecedores, complementando Silva, Ribeiro e Rodrigues (2004). Os hardwares incluem servidores, mainframes, computadores, dispositivos móveis e de saída de dados, consistindo na tecnologia de processamento computacional, armazenamento, entrada e saída de dados. Enquanto isso, os softwares incluem os softwares aplicativos, que possuem tarefa específica solicitada pelo usuário final, e os softwares de sistema, cuja função é administrar os recursos e atividades do computador (LAUDON; LAUDON, 2010).

A tecnologia de redes e telecomunicações é responsável por conectar dados de clientes e fornecedores através da operação de redes internas, sites, e da conexão com outros sistemas computacionais por meio da internet (LAUDON; LAUDON, 2010). Por fim, Laudon e Laudon (2010) consideram os serviços como componentes da infraestrutura de tecnologia da informação, uma vez que as empresas precisam incluir o fator humano na gerência dos outros componentes para suas atividades diárias.

Em relação aos serviços citados, Silva, Ribeiro e Rodrigues (2004) entendem que o contexto no qual as pessoas trabalham também deve ser levado em consideração na formulação de um sistema de informação demandado, ao passo que a tecnologia da informação deve dar suporte aos sistemas, emergindo como oferta de solução para adequação dos mesmos à realidade. A Figura 2 ilustra esse contexto.

Figura 2 - Sistemas de informação e tecnologia da informação

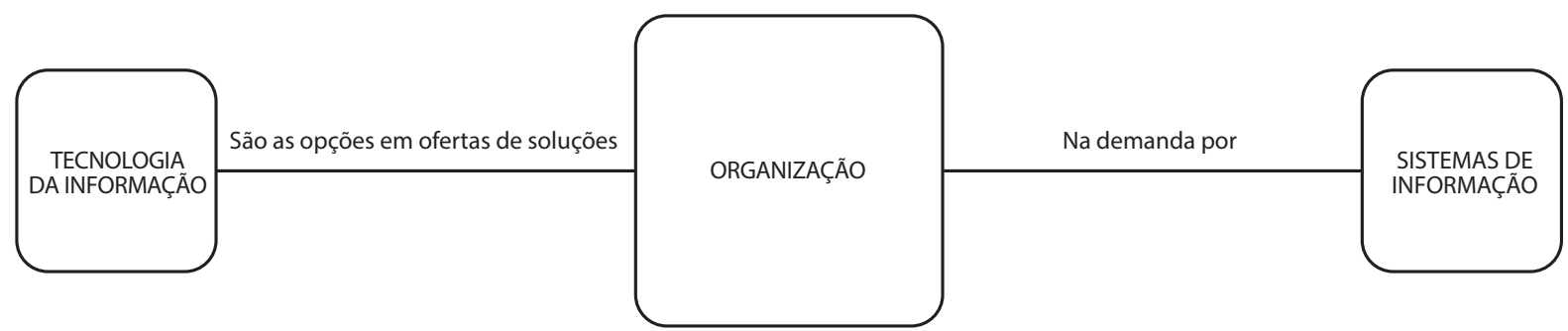

Fonte: Silva, Ribeiro e Rodrigues (2004, p. 3)

Tanto as tecnologias da informação, quanto os sistemas de informação objetivam trazer para as organizações que os utilizam seis benefícios: sobrevivência, relacionamento estreito com clientes e fornecedores, novos produtos ou serviços, vantagem competitiva, excelência operacional e melhor tomada de decisões (LAUDON; LAUDON, 2010).

A sobrevivência das empresas é afetada principalmente em alguns setores, como o bancário. Neste setor, existe a necessidade de conexão com redes nacionais e internacionais, uso de caixas eletrônicos, serviços via internet etc. Além disso, os governos obrigam as empresas a manterem uma série de registros de suas atividades para possíveis auditorias, tornando assim as tecnologias e os sistemas de informação necessários 
para a sobrevivência da mesma (LAUDON; LAUDON, 2010).

O estreitamento no relacionamento com os clientes e fornecedores é visto por Laudon e Laudon (2010) como outro benefício, porque os dados e as possibilidades geradas pela utilização das tecnologias e sistemas fazem as empresas conhecerem mais do ambiente em que estão inseridas. Assim, elas poderão atender melhor a clientes e fornecedores, ofertando produtos e formas de entrega de valor que os primeiros buscam, impulsionando as vendas. Desta forma, a matéria-prima comprada dos segundos será maior, permitindo à empresa a possibilidade de conseguir menores preços nas negociações.

Os novos produtos, serviços e modelos de negócios relacionam-se com o tópico anterior com a entrega de valor gerada para os clientes. Laudon e Laudon (2010) citam o sucesso atual da indústria fonográfica que inexistia nos anos 2000. Neste caso, a Apple rompeu com modelo antigo de negócios na distribuição de músicas e lançou sua própria plataforma para o iPod.

A vantagem competitiva poderá ser conquistada caso a empresa atinja um ou mais dos objetivos citados, sugerindo que esteja desempenhando melhor suas funções do que seus concorrentes, impactando positivamente na formação de seu lucro (LAUDON; LAUDON, 2010).

Já a excelência operacional ocorre quando as tecnologias e sistemas de informação aperfeiçoam a eficiência, a eficácia e a produtividade das operações da organização (LAUDON; LAUDON, 2010). Laurindo et al (2001) busca conceituar eficiência e eficácia para destacar o papel da tecnologia da informação nas organizações.

A eficiência significa fazer bem as coisas, enquanto eficácia significa fazer as coisas certas. A eficiência está associada ao uso dos recursos, enquanto a eficácia está associada com a satisfação das metas, objetivos requisitos. Eficiência está relacionada com aspectos internos à atividade de Tl e a adequada utilização dos recursos, enquanto que a eficácia confronta os resultados das aplicações de TI com os resultados no negócio das empresas e os possíveis impactos de sua operação e estrutura. Ser eficaz em TI significa utilizá-la para alavancar o negócio da empresa, tornando-a mais competitiva (LAURINDO et al, 2001, p.162).

Para encerrar, a melhor tomada de decisões é outro benefício trazido pelo uso das tecnologias e sistemas de informação. Evita-se o mau uso dos recursos disponíveis e respostas ineficientes ao mercado, que podem impactar na perda de clientes (LAUDON; LAUDON, 2010).

\subsection{Sistemas de Informação}

A informação pode ser definida pelo significado que o homem atribui a um dado, sendo este último o fato em sua forma primária (SILVA; RIBEIRO; RODRIGUES, 2004). Desta forma, a informação para Silva, Ribeiro e Rodrigues (2004, p. 35) é "um conjunto de fatos organizados de tal forma que adquirem valor adicional além do valor do fato em si", e tem o propósito de "habilitar a organização a alcançar seus objetivos pelo uso eficiente dos recursos disponíveis". Já "sistemas" é considerado um conjunto de elementos que se relacionam entre si, onde a totalidade dos mesmos serão maiores do que a soma das partes, almejando no seu relacionamento atingir o objetivo (SILVA; RIBEIRO; RODRIGUES, 2004). Para Mattos (2005), um sistema se constitui de uma coleção de objetos e da relação lógica entre eles, assemelhando o seu comportamento a um organismo. Melo (2002) complementa que os sistemas são existentes na natureza ou criados pelos seres humanos para finalidade determinada, sendo a satisfação desta a sua razão de existência.

Neste sentido, um sistema de informação é para Silva, Ribeiro e Rodrigues (2004, p. 52):

[...] um conjunto de procedimentos organizados que, quando executados, proveem informação de suporte à organização. Um SI em geral processa dados, de maneira informatizada ou não, e os apresenta para os usuários, indivíduos ou grupos, que são responsáveis pela sua interpretação.

A Figura 3 retrata o conceito de sistema de informação. 
Figura 3 - Conceito de Sistemas de Informação (SI)

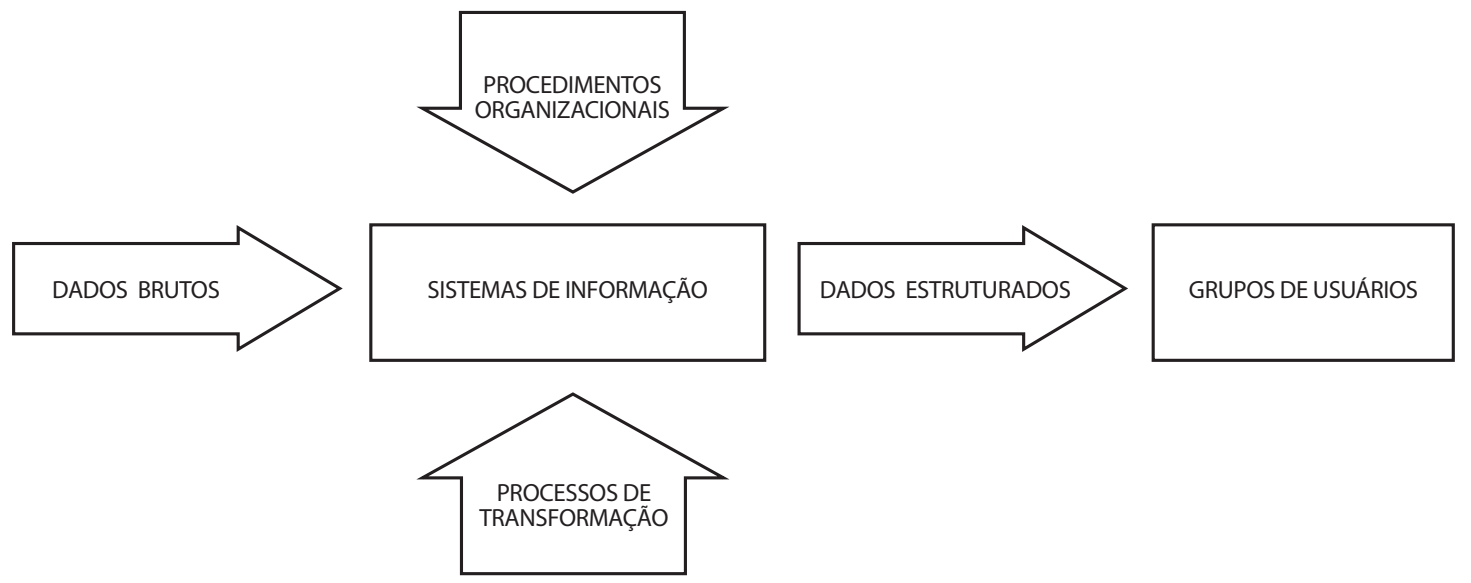

Fonte: Silva, Ribeiro e Rodrigues (2004, p. 83)

Para Mattos (2005, p. 5), um sistema de informação é, na verdade, um sistema com especialização no "processamento e na comunicação de dados (máquinas) ou de informações (organismos vivos)".

Sua constituição inclui, de acordo com Mattos (2005, p. 5-6):

[...] um conjunto de módulos (objetos) de comunicação, de controle, de memórias e processadores, interligados entre si por meio de uma rede com protocolo em comum. As relações lógicas entre esses módulos são definidas pelos programas executados pelo Sistema de Informação.

Mattos (2005) atenta para o fato de que as pessoas devem estar preparadas para utilizar o sistema de informação, seja na aceitação dos sistemas, seja no treinamento adequado para usá-los.

Já Melo (2002, p. 30) sintetiza que os sistemas de informação são "todo e qualquer sistema que tem informações como entradas visando gerar informações de saída". Dessa forma, mais informações são obtidas como produto do funcionamento dos sistemas, permitindo que necessidades venham a ser sanadas (MELO, 2002). Ainda de acordo com o mesmo autor, os sistemas de informação, que tem como matéria-prima a informação, se diferem dos sistemas de produção por não consumi-la, tendo-a disponível como recebida no início do processo (MELO, 2002).

As organizações são sistemas e podem ser entendidas como um conjunto de pessoas e recursos, onde as primeiras se utilizam dos segundos para se atingir objetivos (STAIR; REYNOLDS, 2006; O'BRIEN, 2004). Stair e Reynolds (2006) ressaltam que nas organizações com fins lucrativos o objetivo será o lucro, ao contrário das outras, como grupos sociais e universidades, que não o almejam.

O'Brien (2004, p.18) aponta uma série de aplicações dos sistemas de informação nas organizações, sendo eles o"suporte de seus processos e operações, suporte na tomada de decisões de seus funcionários e gerente, e o suporte em suas estratégias em busca de vantagem competitiva".

\subsection{Implantação dos Sistemas de Informação}

Para Mattos (2005) o desenvolvimento e implantação de um sistema de informação é uma tarefa complexa, chegando a compará-lo com a situação hipotética de se trocar as turbinas de um avião durante seu voo. As dificuldades inerentes a esse processo se relacionam com a forma de envolvimento dos colaboradores e da alta gerência, com a resistência ao uso do novo sistema, com o reprojeto da organização, dentre outras questões de cunho organizacional, humano e tecnológico (MATTOS, 2005). O autor salienta ainda que apenas uma parcela muito pequena dos projetos de sistemas de fato consegue se estabelecer, enquanto a maioria é abandonado ou refeito. Os autores também se atentam para a questão humana nos sistemas de informação, alegando que para funcionarem corretamente, os usuários devem alimentá-los de dados (LAUDON; LAUDON, 2010; STAIR; REYNOLDS, 2006; MATTOS, 2005). Sendo assim, aqueles que se utilizam dos sistemas de informação devem estar aptos e treinados a usá-los.

No Quadro 1, sugere-se um planejamento por meio de PERT (Program Evaluation and Review Technique) para a implantação de um novo sistema. 
Quadro 1 - Etapas para a Implantação de um novo sistema

\begin{tabular}{|c|c|c|}
\hline Ordem & Etapas & Sistema \\
\hline 1 & Levantamento das necessidades & $\begin{array}{l}\text { Verificar de que o usuário necessita, de como as rotinas } \\
\text { devem ser realizadas, o que deve permanecer, etc. }\end{array}$ \\
\hline 2 & Elaboração de testes & $\begin{array}{l}\text { Se aprovado o sistema, selecionar o equipamento mais } \\
\text { adequado e os softwares necessários a eles, tendo em } \\
\text { vista uma vida útil de "x"anos. Testes piloto para verificar } \\
\text { a funcionalidade do sistema. Elaboração de manuais de } \\
\text { operação e do usuário. }\end{array}$ \\
\hline 3 & Treinamento & Ensinar como o usuário deverá usar o novo sistema. \\
\hline 4 & Implantação & $\begin{array}{l}\text { Substituição das rotinas antigas pelas novas, ou } \\
\text { instalação de novos procedimentos. }\end{array}$ \\
\hline 5 & Manutenção & $\begin{array}{l}\text { Assistência ao usuário (help desk). Alterações no } \\
\text { sistema (bugs, novas tabelas, etc.) durante sua vida útil. }\end{array}$ \\
\hline
\end{tabular}

Stair e Reynolds (2006) argumentam sobre a decisão da empresa de produzir seu próprio sistema de informação ou comprá-lo externamente. Em síntese, um sistema desenvolvido pela própria organização pode atender melhor às suas necessidades, no entanto existe a possibilidade de ser custoso em relação a um produzido por terceiro, e vice-versa. Outra saída são aqueles sistemas desenvolvidos por outras empresas que podem ser modificados e funcionar em conjunto com outros sistemas já existentes, chamados por Stair e Reynolds (2006) de interface de software. Neste sentido, os autores sugerem os passos para a implantação de um sistema de informação adquirido de outra organização, apresentados na Figura 4.

• Aquisição de hardware

Nota-se que tanto no Quadro 2 quanto na Figura 4, foram levadas em consideração variáveis relacionadas ao usuário em pontos chave do processo, como treinamento e aceitação, corroborando com as afirmações de Mattos (2005), de que pessoas são as maiores causas de insucessos na implantação de sistemas.

Para se obter um grau de certeza maior de que o sistema implantado funciona corretamente, Stair e Reynolds (2006) sugerem que seja feita uma revisão do mesmo, levando-se em consideração o desempenho e benefícios do sistema implantado em comparação com aquele que havia sido desenvolvido inicialmente. Para tal, a revisão pode ser feita através de eventos, como erros no sistema ou introdução de novos produtos no mercado, dando um caráter contínuo de melhoria e atualização. Outro tipo de revisão é a induzida pelo tempo, onde o sistema é revisado de maneira programada a cada período de tempo (STAIR; REYNOLDS, 2006). 


\subsection{Sistemas de Informação na Administração Pública}

A eficiência no uso dos recursos públicos nestas reformas sofreu influência do uso de tecnologias da informação e de sua aplicação nas atividades do governo nesse período. Soma-se os benefícios trazidos normalmente por tais tecnologias da informação a possibilidade de maior interação dos cidadãos com as atividades governamentais e de maior transparência no uso dos recursos. Este somatório de mudanças e vantagens é conhecido por e-gov ou "governo eletrônico" (CAPELLA, 2010; SIQUEIRA NETO; MENEZES, 2013).

Entende-se por e-gov ou "governo eletrônico" o uso da tecnologia da informação e da internet aplicados na administração pública, visando melhorar os serviços governamentais e prover informações aos "clientes", que neste caso são cidadãos, além de se utilizar a tecnologia para gerar eficiência operacional no seu âmbito interno. Outra aplicação considerada é o uso dos recursos tecnológicos para o sigilo e segurança das informações (SILVA; RIBEIRO; RODRIGUES, 2004). No mesmo sentido, Capella (2010, p. 7) define o e-gov como "um conjunto de ferramentas baseadas da TI que possibilitariam transformações concretas na gestão pública".

Enriquecendo as definições de governo eletrônico, Medeiros e Guimarães (2004) apresentam um resumo que contém contribuições de várias organizações (Quadro 2).

Quadro 2 - Definições de governo eletrônico

\begin{tabular}{|l|l|}
\hline \multicolumn{1}{|c|}{ Definições } & Fontes \\
\hline $\begin{array}{l}\text { Governo eletrônicorefere-seao uso, poragências governamentais, detecnologias } \\
\text { de informação (como redes de longa distância, Internet e computação móvel) } \\
\text { capazes de transformar as relações com cidadãos, empresas e outras unidades } \\
\text { do governo. Essas tecnologias podem servir a diferentes fins, como: melhor } \\
\text { prestação de serviços aos cidadãos, interações mais eficazes com empresas e a } \\
\text { indústria, empowerment do cidadão por meio do acesso a informações ou mais } \\
\text { eficiência na administração governamental. }\end{array}$ & Banco Mundial (2003) \\
\hline $\begin{array}{l}\text { Governo eletrônico ou e-governo significa prover acesso público via Internet a } \\
\text { informações sobre os serviços Office oferecidos pelos departamentos centrais } \\
\text { do governo e suas agências, habilitando o público à condução e à conclusão de } \\
\text { transações para tais serviços. }\end{array}$ & National Audit (2002, p. 1) \\
\hline $\begin{array}{l}\text { O termo 'e-government' [utilizado em inglês para denominar o governo } \\
\text { eletrônico] aborda o uso de novas tecnologias de informação e comunicação } \\
\text { pelos governos, aplicadas a todas as suas funções. }\end{array}$ & OCDE (2001, p. 2) \\
\hline $\begin{array}{l}\text { E-governo é definido como: utilização da Internet e da web para ofertar } \\
\text { informações e serviços governamentais aos cidadãos. }\end{array}$ & Nações Unidas (2002, p. 1) \\
\hline $\begin{array}{l}\text { O termo governo eletrônico é definido como a oferta e troca de informações } \\
\text { e serviços governamentais on-line para cidadãos, empresas e outras agências } \\
\text { governamentais }\end{array}$ & INTOSAI (2003, p.3) \\
\hline
\end{tabular}

Fonte: Medeiros e Guimarães (2004, p. 51)

Assim como Capella (2010) e Silva, Ribeiro e Rodrigues (2004), no que tange os benefícios do e-gov, Medeiros e Guimarães (2004) acrescentam o aumento da arrecadação do governo, além da possibilidade do aumento de transparência das atividades do mesmo para com a população.

Existem quatro estágios de evolução do e-gov, conforme o Quadro 3.

Quadro 3 - Estágios do e-gov

\begin{tabular}{|c|l|}
\hline Estágio & \multicolumn{1}{|c|}{ Características } \\
\hline Primeiro & $\begin{array}{l}\text { Utiliza-se a internet neste estágio apenas para informar os cidadãos sobre os serviços } \\
\text { prestados pela administração pública. }\end{array}$ \\
\hline Segundo & $\begin{array}{l}\text { A internet é usada para a realização de transações online, como a cotação de preços dos } \\
\text { Pregões Eletrônicos, que maximiza a competição e minimiza os custos do governo e do } \\
\text { pagamento de impostos e taxas por parte dos cidadãos. Aqui ocorrem as transações do tipo } \\
\text { G2B (Government to Business ou Governo para Negócios) e G2C (Government to Citizen ou } \\
\text { Governo para Cidadãos). }\end{array}$ \\
\hline
\end{tabular}




\begin{tabular}{|c|l|}
\hline Terceiro & $\begin{array}{l}\text { Neste estágio se encontram as transações G2G (Government to government ou Governo para } \\
\text { Governo) que buscam integrar os sistemas de informação dos níveis de governo (federal, } \\
\text { estadual e municipal) e aqueles do mesmo nível. }\end{array}$ \\
\hline Quarto & $\begin{array}{l}\text { Estágio chamado de"Government Inteligency".Évisto em pouquíssimos países, exemplificados } \\
\text { por Reino Unido e Cingapura. Neste estágio as informações são utilizadas para se gerar } \\
\text { inteligência para os governos. }\end{array}$ \\
\hline
\end{tabular}

$$
\text { Fonte: Silva, Ribeiro e Rodrigues (2004, p. 201) }
$$

Pode-se perceber pelo Quadro 3 que existe uma relação direta entre o estágio do e-gov percebido e o grau de desenvolvimento tecnológico de um país. O fato de que apenas poucos países se encontrarem no Terceiro e Quarto estágios reforçam essa ideia.

\subsection{E-gov no Brasil}

A utilização do governo eletrônico na administração pública brasileira compreende três fases, de acordo com Diniz (2006 apud CAPELLA, 2010). A primeira delas é compreendida entre os anos de 1970 e 1992, onde foi buscada a automação de procedimentos organizacionais almejando ganhos de eficiência e controle. Os sistemas desta fase se encontravam no nível operacional das organizações, substituindo operações manuais por procedimentos informatizados.

A segunda fase, ocorrida entre os anos de 1993 e 1998, foi dedicada à gestão interna, alimentando a alta burocracia de informações gerenciais completas para auxiliar na tomada de decisão. Almejaram também o apoio à prestação de serviços e informações aos usuários dos serviços públicos (DINIZ, 2006 apud CAPELLA, 2010). Um exemplo desta etapa foi o"Projeto Cidadão", que continha medidas desburocratizantes, além de um sistema para reclamações e sugestões por meio de telefone, fax e e-mail. O “Projeto Cidadão" era parte de um conjunto de ações da Reforma da Administração Pública do governo de Fernando Henrique Cardoso (BRASIL, 1995 apud CAPELLA, 2010).

Por fim, a terceira fase vai do ano de 1999 até os dias atuais. Sua principal característica é a criação de portais governamentais (DINIZ, 2006 apud CAPELLA, 2010). Um ponto importante desta fase, que ainda se encontra em pleno desenvolvimento, foi a criação do Departamento de Governo Eletrônico pelo governo Lula no ano de 2004, submetido a Secretaria de Logística e Tecnologia da Informação (SLTI) do Ministério do Planejamento, Orçamento e Gestão (MPOG).

No último ranking referente à qualidade de serviço de "governo eletrônico" publicado pela ONU em 2014, o Brasil se encontra na 57a posição considerando 135 países, com 0,6008 ponto numa escala de 0 a 1. A pontuação considera quantitativamente as variáveis capital humano, infraestrutura de telecomunicações e serviços públicos on-line. Tal estudo aponta que o país deve melhorar sua infraestrutura de comunicação, aperfeiçoar seus serviços oferecidos on-line, além de fornecer mais banda larga aos usuários para sair da camada intermediária do ranking (ONU, 2014).

Denota-se que a segunda etapa do Governo Eletrônico, que foi dedicada à eficiência interna, ainda se faz presente. Por exemplo, alguns equipamentos do Sistema Único de Assistência Social (SUAS) fazem a assinatura de um software para o desenvolvimento de suas atividades, visando melhorar sua gestão e o serviço prestado. Tal fato sugere que as etapas do e-gov ainda se fazem presentes e podem ocorrer ao mesmo tempo.

\section{O SISTEMA ÚNICO DE ASSISTÊNCIA SOCIAL}

De acordo com o site do Ministério do Desenvolvimento Social e do Combate à Fome (MDS), o Sistema Único de Assistência Social (SUAS) está presente em todo o país, articulando esforços e recursos nos municípios, estados e União. Seu objetivo é:

[...] garantir a proteção social aos cidadãos, ou seja, apoio a indivíduos, famílias e à comunidade no enfrentamento de dificuldades, por meio de serviços, benefícios, programas e projetos que constituem como apoio aos indivíduos, famílias e para a comunidade no enfrentamento de suas dificuldades (BRASIL, 2015).

Em linhas gerais, o SUAS possui dois tipos de proteção social: a Proteção Social Básica e Proteção Social Especial. O primeiro tipo relaciona-se com riscos sociais e pessoais, contemplando programas, projetos e benefícios para aqueles que se encontram em um quadro de vulnerabilidade social. Estão inclusos aqui o Benefício de Prestação Continuada da Assistência Social (BPC), que garante um salário mínimo para idosos e deficientes físicos que não possuem meios de se sustentar, os Benefícios Eventuais, utilizados para situações 
de vulnerabilidade temporária, como morte ou calamidade pública e o Programa de Proteção e Atenção Integral à Família (PAIF), que tem como objetivo evitar a ruptura das famílias vulneráveis, promovendo seu fortalecimento. Já a Proteção Social Especial é destinada a famílias e indivíduos que se encontram ou que já viveram situações de risco, abusos e violações. O Programa de Proteção e Atendimento Especializado a Famílias e Indivíduos (PAEFI) inclui-se neste último e visa proteger seus beneficiários de violações em seus direitos, como violência psicológica, sexual ou física, utilizando-se de medidas socioeducativas. São tratados por este programa casos de tráfico de pessoas, moradores de rua, abandono, trabalho infantil e descriminações em todos seus tipos e formas (BRASIL, 2015).

Seguindo as diretrizes da Constituição de 1988, o SUAS apresenta uma série de mecanismos para que haja participação social em suas atividades, como conselhos, ouvidorias, consultas públicas, mesas de diálogo e negociação e audiências. Em sua gestão, a União formula, apoia, articula e coordena as ações, ao passo que os estados operam dentro de seus limites de acordo com as responsabilidades estabelecidas pela Norma Operacional Básica (NOB/SUAS), conforme mostra o site do MDS. Os municípios por sua vez possuem três níveis de habilitação, que são mostrados pelo Quadro 4.

Quadro 4 - Níveis de Habilitação do SUAS a Nível Municipal

\begin{tabular}{|c|l|}
\hline Níveis & \multicolumn{1}{|c|}{ Características } \\
\hline Inicial & $\begin{array}{l}\text { Inclui os municípios que possuem requisitos mínimos. São eles: a existência e } \\
\text { funcionamento de um conselho, de um fundo para execução dos planos da Assistência } \\
\text { Social e do Programa de Proteção Social Básica }\end{array}$ \\
\hline Básico & Os municípios deste nível possuem autonomia na gestão da Proteção Social Básica \\
\hline Pleno & $\begin{array}{l}\text { Neste nível os munícipios passam a ter autonomia total para gerenciar as ações } \\
\text { socioassistenciais. }\end{array}$ \\
\hline
\end{tabular}

Fonte: Brasil (2015)

Para desempenhar suas funções o SUAS conta com uma rede de unidades públicas para atendimento dos seus beneficiários. Segundo site do Ministério do Desenvolvimento Social e Combate à Fome (MDS), as unidades são:

- Centro de Referência de Assistência Social (CRAS): Considerado a porta de entrada da assistência social, o CRAS é um local público localizado em áreas de vulnerabilidade social. Busca auxiliar a comunidade onde está instalado na busca de solução para os problemas daquela área, como transporte público, violência, ausência de espaços de lazer etc. Também oferece os serviços de assistência social e procura fortalecer os laços familiares e comunitários dos usuários.

- Centro de Referência Especializado de Assistência Social (CREAS): Voltado para famílias ou indivíduos que se encontram em situação de vulnerabilidade e violação de seus direitos, o CREAS deve obrigatoriamente ofertar o PAEFI. Além disso, busca fornecer orientação jurídica e estimular a mobilização social da localidade.

- Centro de Referência Especializado para População em Situação de Rua (Centro POP): Como sugere seu nome, o Centro POP deve obrigatoriamente ofertar o Serviço Especializado para Pessoas em Situação de Rua, almejando o convívio e socialização da sua população alvo. Suas ações incluem a guarda de pertences, a higiene pessoal, a alimentação e provisão de documentos de seus beneficiários.

- Centro Dia de Referência Para Pessoa com Deficiência e suas Famílias: Unidade pública destinada ao atendimento de jovens e adultos deficientes que dependem de outras pessoas e de suas famílias, justificando o fato de que deve, obrigatoriamente, oferecer o Serviço de Proteção Social Especial Para Pessoas com Deficiência e suas Famílias. Busca apoiar e orientar as famílias de seus usuários a convivência em grupo, fortalecendo as relações sociais e familiares.

- Unidades de Acolhimento: Destinadas a pessoas em situação de abandono ou afastadas do seu núcleo familiar. Casos de ameaças e violação de direitos também estão inclusos. Em síntese, as Unidades de Acolhimento servem como moradia provisória até que o indivíduo possa retornar para sua família. Contemplam crianças, adolescentes, adultos, famílias, pessoas idosas, deficientes, mulheres em situação de violência e situações de calamidade pública.

Dada a complexidade por estar em três esferas governamentais, além do número de beneficiários envolvidos e da normatividade própria que regula suas atividades, o SUAS necessita possuir uma gestão compatível com tamanho fluxo de informações. Para atender tal demanda, foi criado o GESUAS para organizar e otimizar o atendimento de seus usuários. 


\section{METODOLOGIA}

A presente pesquisa pode ser definida como qualitativa. Para Godoy (1995, p. 62), em geral as pesquisas desta natureza possuem características semelhantes entre si:

[...] o ambiente como fonte direta de dados e o pesquisador como instrumento principal. [...] a pesquisa qualitativa é descritiva. [...] O significado que as pessoas dão as coisas são a preocupação essencial do investigador. [...] pesquisadores utilizam o enfoque indutivo como análise de seus dados.

Em relação aos fins, é classificada como descritiva, uma vez que os dados coletados não aparecem sob forma numérica. Nesse tipo de pesquisa podem ser analisadas entrevistas, anotações de campo, fotografias, vídeo, desenhos e outros tipos de documentos (GODOY, 1995). Para se cumprir os objetivos propostos por esta pesquisa utilizou-se do estudo de caso único, definido por Yin (2010), como uma investigação empírica para se aprofundar em determinado fenômeno da vida real. É único por se tratar apenas da cidade de Viçosa. Não foram feitas comparações com outras localidades, tampouco se realizaram estudos de múltiplos casos.

Sendo assim, foram entrevistados atores estratégicos envolvidos com o software em questão: o seu desenvolvedor, descrito como Ator 1, e dois funcionários da Assistência Social de Viçosa que estavam presentes nos primeiros testes e versões do GECRAS e GECREAS, intitulados como Ator 2 e Ator 3. Atualmente, estes últimos trabalham no Departamento de Políticas Sociais da mesma secretaria, sendo o Ator 2, coordenador do Setor de Proteção Básica, e o Ator 3, o chefe do referido departamento.

A primeira entrevista realizada foi com o Ator 1, no dia 8 de outubro de 2015, em sua empresa. Já os Atores 2 e 3 foram entrevistados no dia 20 de outubro do mesmo ano, na Secretaria de Assistência Social de Viçosa, por indicação da atual secretaria. Todas as entrevistas foram gravadas e transcritas posteriormente.

Ao saber que, embora o software tenha sido criado para suprir uma demanda da cidade de Viçosa e que a mesma não faz a assinatura do mesmo atualmente, investigou-se seu processo de implantação, as demandas que o originaram, bem como suas implicações dimensões organizacional, tecnológica e humana.

O método utilizado para o tratamento das entrevistas coletadas foi à análise de conteúdo. Esta técnica pode ser empregada tanto em pesquisas quantitativas, quando qualitativas, buscando identificar o que é dito a respeito do tema em questão (VERGARA, 2005). Bardin (1977, p. 42) o define como:

Um conjunto de técnicas de análise de comunicações visando obter, por procedimentos sistemáticos e objetivos de descrição do conteúdo de mensagens, indicadores (quantitativos ou não) que permitam a inferência de conhecimentos relativos às condições de produção/ recepção (variáveis inferidas) destas mensagens.

Vergara (2005) sugere que o método possa ser utilizado em pesquisas exploratórias ou de verificação, e que, ao fim da coleta de dados, a interpretação caberá ao pesquisador.

Bardin (1977), recomenda a divisão em categorias de análise para o tratamento dos dados coletados. Neste sentido buscou-se a criação de subdimensões dentro das dimensões de sistemas de informação sugeridas por Laudon e Laudon (2010). O Quadro 5 busca retratá-las.

Quadro 5 - Dimensões e Subdimensões do GESUAS

\begin{tabular}{|c|l|}
\hline Dimensões & \multicolumn{1}{|c|}{ Subdimensões } \\
\hline Organizacional & Demandas, Especificidades, Implantação, Barreiras \\
\hline Tecnológica & Ferramentas, Atualização do Sistema, Requisitos para o uso do sistema, Suporte ao usuário \\
\hline Humana & Resistência, Capacitação, Tomada de decisão \\
\hline \multicolumn{2}{|c}{ Fonte: Elaborado pelo autor (2015) }
\end{tabular}

Serão explicitados nos resultados o que cada ator envolvido indica sobre cada categoria na validação dos dados para o cumprimento dos objetivos propostos pela pesquisa.

\section{RESULTADOS}

Os resultados encontrados nas entrevistas e mostrados pelo Quadro 7 serão explicados de forma mais profunda a seguir, juntamente com informações detalhadas a respeito do GESUAS. 


\subsection{O software GESUAS}

A ideia para criação de um software voltado para as Secretarias de Assistência Social surgiu no ano de 2008, na cidade de Viçosa, Minas Gerais. Conforme será explicitado mais adiante, havia uma demanda de gestão da informação nos equipamentos do CRAS e CREAS da cidade. A partir deste ponto, o Ator 1 desenvolveu dois sistemas: o GECRAS, voltado para a proteção básica, e o GECREAS para situações de média complexidade. Após a realização dos testes necessários e do uso dos mesmos, optou-se pela integração de ambos os sistemas em um único software, culminando na criação do GESUAS.

Os municípios que utilizam o software atualmente são: Santana de Cataguases, Alfredo Vasconcelos, Quartel Geral, Capelinha, São Roque de Minas, Dona Inês, Bueno Brandão, Vera, Rio Casca, Catas Altas, Timoteo, Buritis, Andrelândia, Acaiaca, Ilhabela, Coronel Fabriciano, São Gonçalo do Sapucaí, Água Azul do Norte, Chácara, Guimarânia, Congonhal, Ponte Nova, Vargem Bonita, Nepomuceno, São Bento Abade e Dois Corrégos.

Segundo depoimento do responsável pela idealização e desenvolvimento do GESUAS, a construção do programa levou em consideração toda a normatividade que compreende o Sistema Único de Assistência Social disponível no site do Ministério de Desenvolvimento Social e Combate à Fome (MDS). Os documentos utilizados foram: o Formulário Prontuário SUAS, a Tipificação Nacional dos Serviços Socioassistenciais, a Norma Operacional do Sistema Único de Assistência Social (NOB/SUAS 2012), o SUAS e População em Situação de Rua, as Orientações Técnicas do Centro de Referência de Assistência Social (CRAS), as Orientações Técnicas para operacionalização dos Serviços de Convivência e Fortalecimentos de Vínculos, as Orientações Técnicas para os Centros de Referência Especializados de Assistência Social (CREAS), a Resolução n4 da Comissão Intergestores Tripartite (CIT), os Manuais de instruções para o registro das informações especificadas na resolução N04/2011 da Comissão Intergestores Tripartite (CIT) para CRAS e CREAS, os Manuais Censo do CRAS e CREAS, a Lei Orgânica de Assistência Social (LOAS), a Política Nacional de Assistência Social, o Protocolo de Gestão Integrada de Serviços, Benefícios e Transferência de Renda no Âmbito do SUAS, as Orientações Técnicas sobre o PAIF (Volumes 1 e 2), e por fim as Orientações Técnicas sobre o Serviço de Convivência e Fortalecimento de Vínculos para Crianças e Adolescentes.

De acordo com informações constantes no site do GESUAS, seu principal objetivo é organizar de maneira sistemática as informações necessárias para o atendimento dos beneficiários, trazendo o histórico de acompanhamento familiar e outros dados requeridos pelo Ministério do Desenvolvimento Social e Combate à Fome (MDS), auxiliando a tomada de decisão por parte dos gestores municipais. Desta maneira, nota-se que a intencionalidade é propiciar maior agilidade e facilidade de lidar com a burocracia pública. Assim, a demanda pela qual emerge a necessidade do GESUAS liga-se a um problema recorrente dos processos de gestão públicos: a burocratização estatal.

O software disponibiliza também o registro de atividades mensais da unidade de assistência social, do Plano de Acompanhamento Familiar (PAF) e do Plano Individual de Atendimento (PIA). Ressalta-se que para garantir a proteção e confidencialidade das informações que alimentam o sistema é necessário possuir o nome de usuário e login cadastrados para tal.

\subsection{Dimensão Organizacional}

Foram analisadas nesta dimensão as demandas, as especificidades, a implantação, e as barreiras que envolvem o software em questão. A demanda para o desenvolvimento surgiu com a instalação dos equipamentos do CRAS, CREAS e também do Programa Bolsa Família por parte do Governo Federal em todos os municípios do país por meio das Secretarias de Assistência Social. Estes serviços buscam atender indivíduos ou famílias em situação de vulnerabilidade. Os atores 2 e 3 compartilham da mesma visão sobre esta subdimensão.

Por sua vez, o Ator 1, ao ser motivado por uma secretária de assistência social, resolveu desenvolver um software voltado para o atendimento do CRAS primeiramente. O sistema recebeu o nome de GECRAS e foi criado no ano de 2008.

Atento para a especificidade do setor, que possui uma série de leis, normas, portarias e procedimentos impostos pelo Ministério do Desenvolvimento Social e Combate à Fome (MDS) pela Lei Orgânica da Assistência Social (LOAS), o Ator 1 incluiu em seu sistema a capacidade de se fazer relatórios obrigatórios pelas Secretarias de Assistência Social de maneira automática. Um exemplo é o Relatório Físico Mensal de Serviços e Benefícios Socioassistenciais, explicitado pela Figura 5. Antes da implantação do GESUAS o mesmo era feito à mão pelos funcionários públicos. Com o uso do sistema, esperava-se economizar papel e reduzir custos da impressão e envio de documentos físicos. A precisão e redução das chances de duplicidade de informações nos relatórios também eram almejados após a instalação do programa. Tais benefícios corroboram com a excelência 
operacional, mencionada por Laudon e Laudon (2010).

Figura 5 - Relatório de Serviços e Benefícios de PSB

\begin{tabular}{|c|c|}
\hline \multicolumn{2}{|l|}{ Demonstrativo Fisico Mensal de oferta de Serviços e Beneficios Socioassistenciais de PSB } \\
\hline \multicolumn{2}{|l|}{ Mês de referência: Agosto / 2013} \\
\hline \multicolumn{2}{|l|}{ 1. Serviço de Proteção e Atendimento Integral à Família - PAIF } \\
\hline & Total \\
\hline Número total de familias em acompanhamento pelo PAlF & 6 \\
\hline Número total de famílias inseridas no acompanhamento do PAIF, durante o mês de referência & 2 \\
\hline \multicolumn{2}{|l|}{ 2. Serviço de Convivência e Fortalecimento de Vínculos - SCFV } \\
\hline & Total \\
\hline Número total de individuos atendidos no SCFV, durante o mês de referência & 1 \\
\hline Outros & 1 \\
\hline \multicolumn{2}{|c|}{ 3. Serviço de Proteção Social Básica no Domicílio para Pessoas com Deficiência e Idosos } \\
\hline & Total \\
\hline Pessoas com Deficiência & 0 \\
\hline Idosos & 0 \\
\hline Número total de pessoas com deficiência e idosos identificados e acompanhados no serviço, no mês de referência & 0 \\
\hline \multicolumn{2}{|l|}{ 4. Benefícios Eventuais } \\
\hline & Total \\
\hline Número total de famililas atendidas em Beneficicios Eventuais, no mês de refererência & 0 \\
\hline
\end{tabular}

Fonte: dados da pesquisa (2015)

A implantação do software por sua vez, se inicia com a migração de dados do Cadastro Único para o GESUAS. Neste processo, os dados são tratados, verificando-se se há duplicidade de informações e erros nos nomes das localidades e logradouros dos beneficiários. Após esta etapa, é feito o treinamento da equipe. $\mathrm{O}$ Ator 1 argumenta que em cidades maiores o treinamento deve ser realizado por nível de complexidade.

A Figura 6 elucida o processo de implantação do GESUAS nas Secretarias de Assistência Social dos municípios assinantes. Nota-se que este processo é semelhante ao sugerido por Mattos (2005).

Figura 6 - Fluxograma de Implantação do GESUAS

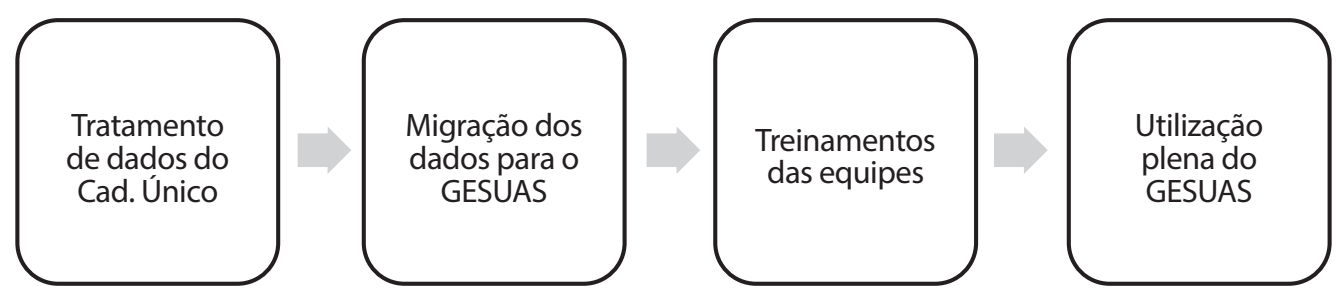

Fonte: Elaborado pelo autor (2015)

Para finalizar o tópico da dimensão organizacional, discorrer-se-á sobre as barreiras identificadas. A primeira a ser tratada é a vontade política. No caso da cidade de Viçosa, ocorreu a cassação do prefeito quando o GESUAS já havia passado pela fase de testes e estava as vias de ser comprado pela prefeitura. Com a mudança na conjuntura política do município, que influenciou também na Secretaria de Assistência Social, conforme relata o Ator 3. A outra barreira organizacional encontrada, na visão do mesmo ator, são os processos burocráticos da administração pública, que necessitam passar pelo departamento jurídico e no setor de compras. A impossibilidade de compra direta de um software implica na realização de uma licitação, cujo prazo necessário não acompanha a demanda da Secretaria de Assistência Social. O processo jurídico de contratação também compartilha da mesma crítica na visão do Ator 3.

\subsection{Dimensão Tecnológica}

O aspecto tecnológico do GESUAS discorrerá sobre suas ferramentas, a atualização do sistema, seus requisitos para funcionamento e o suporte oferecido ao usuário do sistema. Algumas informações contidas nas imagens serão encobertas para se manter sigilo das informações pessoais do usuário e dos beneficiários de programas sociais. 
Conforme as funções do gestor de assistência social municipal, que são monitorar e avaliar os serviços que são prestados, o software engloba uma série de funções para que sejam colocados os dados necessários. A Figura 7 mostra o menu de ferramentas do GESUAS.

Figura 7 - Ferramentas do GESUAS

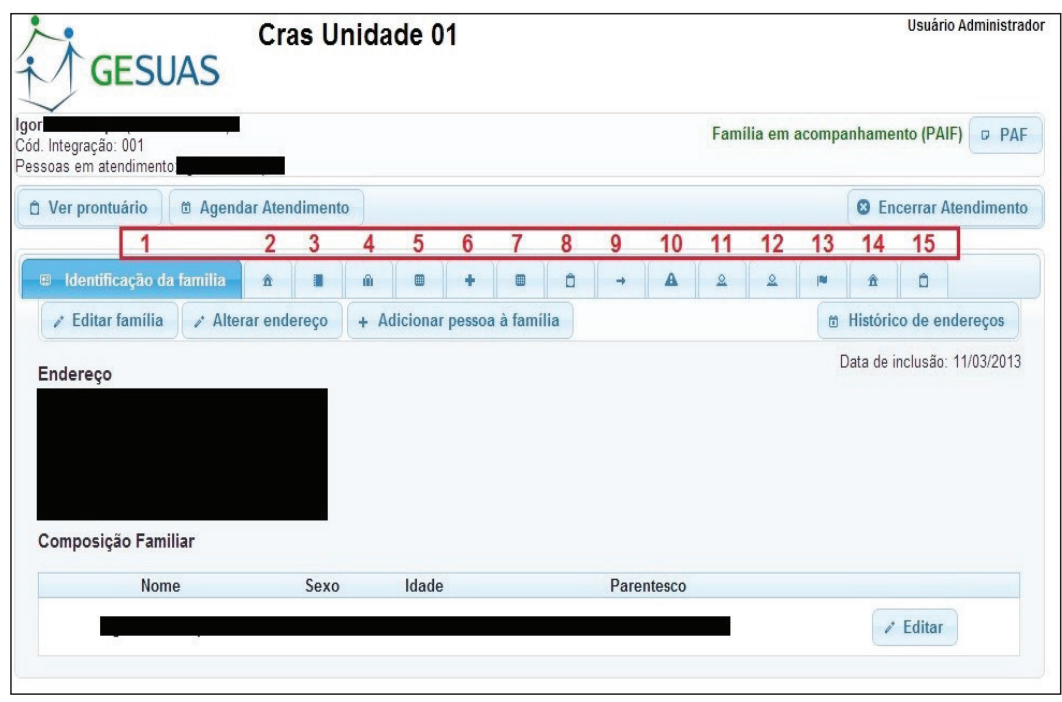

Fonte: dados da pesquisa (2015)

As ferramentas mostradas são representadas por números de 1 a 15 diante da impossibilidade de retratar todas com suas respectivas imagens. Logo, as respectivas funcionalidades do menu são: 1-Identificação da Família, 2-Condições Habitacionais, 3-Condições Educacionais, 4-Condições de Trabalho e Rendimentos, 5-Programas Sociais, 6-Condições de Saúde, 7-Acesso a Benefícios Habituais, 8-Ações Coletivas, 9Encaminhamentos, 10-Descumprimento e Condicionalidade, 11-Convivência Familiar e Comunitária, 12Situações de Violência, 13-Histórico de Medias Socioeducativas (MSE), 14-Histórico de Acolhimento e 15Observações. Nota-se que o sistema mescla ao mesmo tempo uma interface intuitiva com todo o instrumental necessário para seus usuários desempenharem suas funções. Outros aspectos importantes são a maior precisão das informações, pois se evita a duplicidade das mesmas, e o uso e acúmulo de papéis. Relatórios escritos podem ser perdidos e são mais difíceis de compartilhar entre os funcionários, enquanto o uso online possibilita a visualização de todas as informações por parte dos usuários.

Mesmo com as ferramentas já existentes, o Ator 1 trabalha com a possibilidade de aumentá-las conforme a normatividade da Assistência Social se altera, além de atualizar o sistema constantemente com mais funções. O site do software também possui espaço para o usuário elogiar, criticar e sugerir mudanças no sistema, norteando as tomadas de decisão do Ator 1 naquilo que deve ser ou não alterado no GESUAS.

A atualização do GESUAS vai ao encontro de Mattos (2005), que reafirma o papel de manter o sistema atualizado para se adicionar novas funcionalidades e evitar bugs. Neste caso especificamente, existem os relatórios obrigatórios da Assistência Social, que sofrem alterações em seu corpo à medida que se publicam novos regulamentos e portarias.

O software em questão demanda apenas de internet para o seu funcionamento pleno. O Ator 1 diz que não é necessária uma tecnologia da informação robusta para se utilizar o GESUAS, uma vez que seu uso é online.

Sobre a questão da infraestrutura de tecnologia da informação na Secretaria de Assistência Social, o Ator 3 argumenta que a compra de computadores pode ser um entrave para uso do programa, destacando que no caso de Viçosa a capacitação de funcionários não é a maior barreira. Tal afirmação corrobora com o que foi dito no tópico de Dimensões Organizacionais. A falta de recursos e a imposição de barreiras burocráticas prejudicam a instalação de softwares no setor público, embora existam verbas do Sistema Único de Assistência Sociais (SUAS) específicas para a compra de materiais.

O suporte do programa aproveita-se de seu funcionamento da internet e se faz à distância, o que facilita tanto para a empresa quanto para quem utiliza o sistema. A primeira não precisa se deslocar até a Secretaria de Assistência Social da cidade, enquanto os segundos apenas precisam preencher um formulário online para o atendimento, sanando problemas e dúvidas. A Figura 8 representa a maneira que é feito. 
Figura 8 - Suporte ao usuário

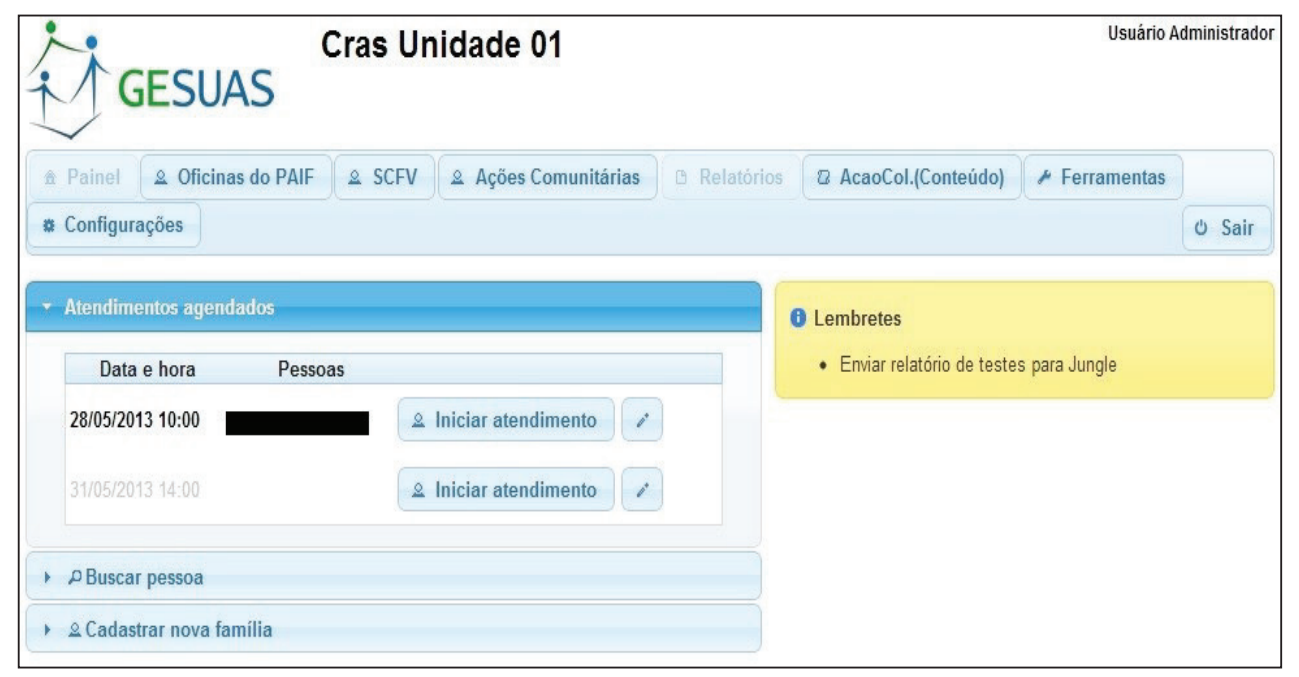

Fonte: dados da pesquisa (2015)

Por outro lado, segundo o Ator 1, ainda existem municípios que têm dificuldade de instalarem internet em suas áreas, o que inviabiliza a utilização e suporte do GESUAS. Esta barreira está ligada com a questão da infraestrutura tecnológica disponível no Brasil, que conforme mostrado anteriormente pelo relatório da ONU, ainda precisa evoluir para atingir estágios superiores. O capital humano, infraestrutura de telecomunicações e serviços públicos online precisam de melhorias para o acesso igualitário dos cidadãos e municípios à rede mundial de computadores.

\subsection{Dimensão Humana}

Esta dimensão abordará a resistência, a capacitação, e a tomada de decisão por parte do usuário do programa. Para o Ator 1, durante a implantação do sistema, foi constatada uma barreira relacionada às pessoas, que possuem dificuldade em usar e aceitar novas tecnologias no ambiente de trabalho, preferindo se utilizar do papel ao computador.

Ressalta-se que os Atores 2 e 3 não mencionaram em suas respostas a resistência dos funcionários em relação à tecnologia. Por outro lado, o Ator 2 considerou a capacitação dos servidores como barreira para a implantação do software na administração pública. Porém, conforme mencionado pelo Ator 1 no tópico anterior, existe um treinamento com a equipe que irá utilizar o GESUAS. A interface simples e indutiva do software também ajuda a mitigar o problema, corroborando o que foi dito por Stair e Reynolds (2006) sobre o treinamento e aceitação do usuário.

Embora o sistema seja importante para a formulação de políticas em assistência social por gerar gráficos com os dados dos beneficiários, das ações da Secretaria e dos principais problemas encontrados, a tomada de decisão será um fator humano. O Ator 1, em seus dizeres, relaciona o papel do gestor municipal com os relatórios oferecidos pelo GESUAS. Na sua visão, ao visualizar os relatórios disponíveis pelo software, o gestor municipal pode identificar problemas comuns em certas áreas, as principais mazelas que afetam indivíduos e famílias, e, a partir desde ponto, elaborar políticas municipais mais eficientes no combate à vulnerabilidade e exclusão social.

A Figura 9 mostra o relatório que separa os atendimentos por tipo. A ferramenta se mostra útil para a tomada de decisão, dado que o gestor pode ter uma visão holística do que ocorreu em determinado período na Secretaria de Assistência Social e personalizar ou se preparar para determinadas situações. 
Figura 9 - Gráficos para a Tomada de Decisão I

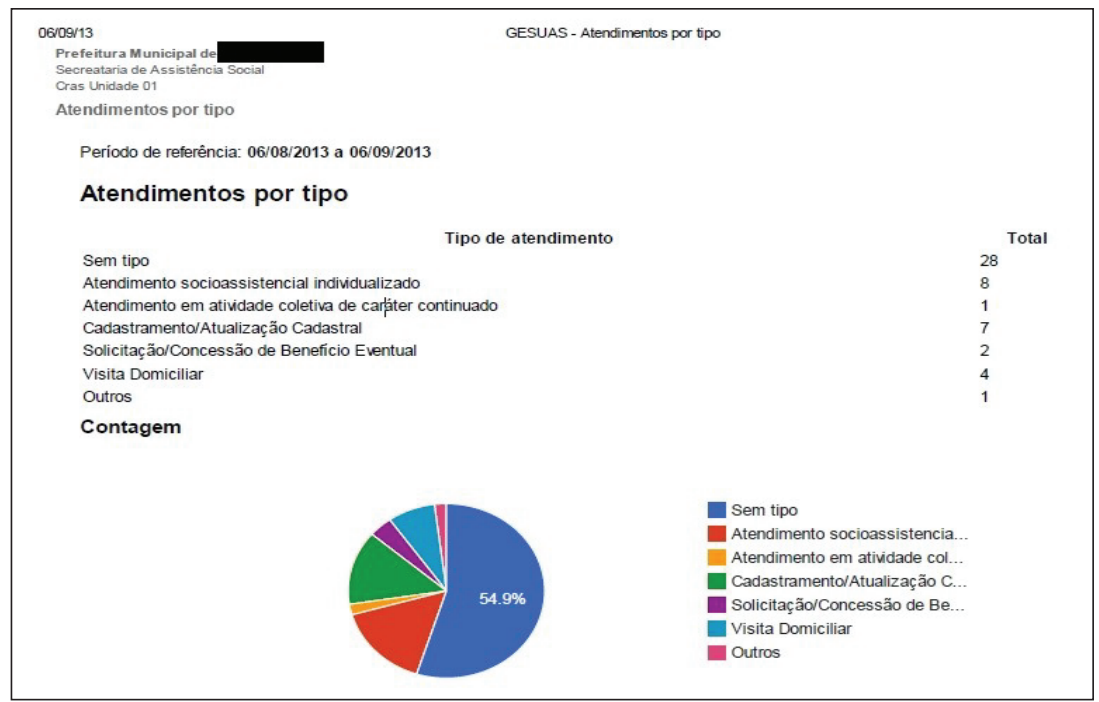

Fonte: dados da pesquisa (2015)

Ao serem perguntadas sobre o que esperavam de um software voltado para assistência social, os atores 2 e 3, em comunhão de pensamento, disseram que é importante o programa gerir e organizar as informações que o alimentam durante o uso cotidiano. Além disso, deve ser capaz de ser entendido pelo usuário, que deverá utilizá-lo em sua plenitude, tanto para a avaliação, quanto para monitoramento.

Percebe-se que ao se desenvolver o GESUAS foram realmente levados em consideração aspectos importantes do fluxo de trabalho, conforme disse o Ator 1. Ao trabalhar online, o sistema permite que qualquer CRAS ou CREAS acesse as informações disponíveis, evitando-se erros no processo. Na Figura 10 é possível visualizar outro tipo de gráfico gerado, desta vez relacionado com as vulnerabilidades identificadas nas famílias atendidas.

Figura 10 - Gráficos para a Tomada de Decisão II

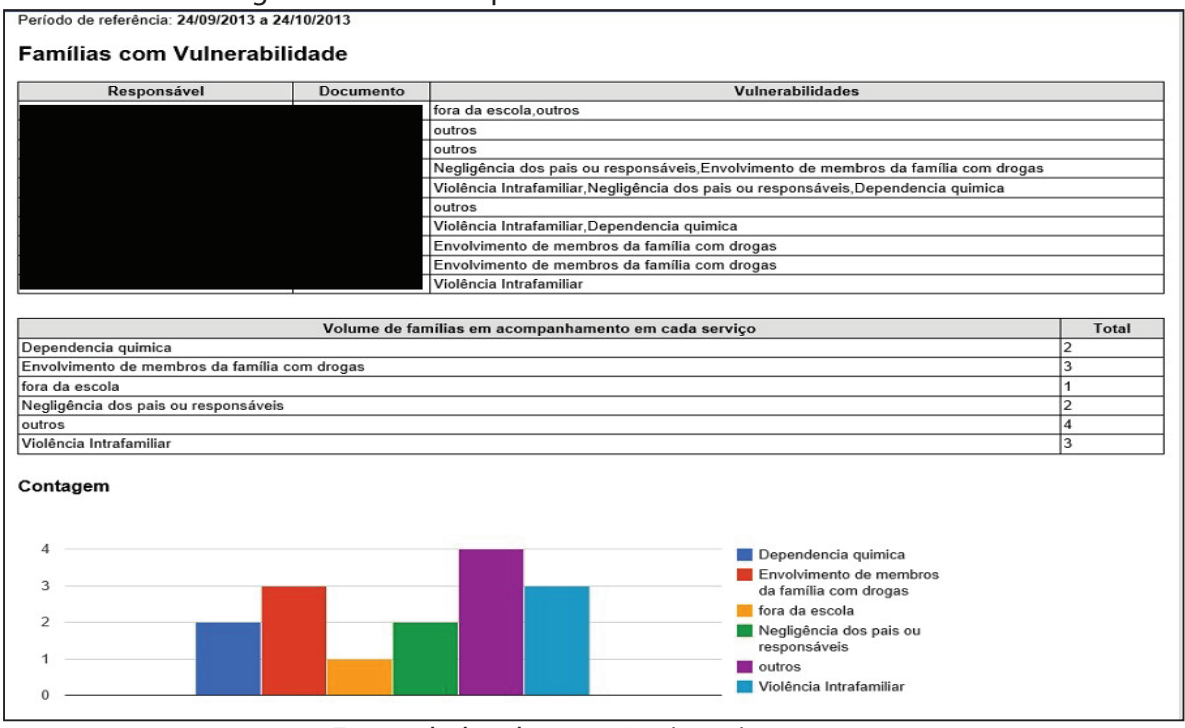

Fonte: dados da pesquisa (2015)

Acredita-se que a possibilidade de conhecer os maiores problemas em determinada localidade facilita a atuação de políticas voltadas para problemas específicos, como uso de drogas e ausência de crianças na escola. Portanto, de acordo as demandas da Secretaria de Assistência Social, expostas pelos Atores 2 e 3, e com as ferramentas oferecidas pelo GESUAS, é possível dizer que o mesmo se mostra útil para a tomada de decisão no âmbito para o qual fora desenvolvido. 


\title{
6 CONCLUSÃO
}

Existe uma série de fatores de sucesso e insucesso ao se implantar sistemas de informação, sejam em organizações privadas ou públicas. No entanto, no caso dessas últimas, percebe-se que há uma complexidade maior em relação às primeiras dado a necessidade de observar as burocracias existentes no âmbito público. Apesar da complexidade do ambiente organizacional, o GESUAS foi exitoso no cumprimento da normatividade publicada pelo MDS e por possuir ferramentas compatíveis com o fluxo de trabalho naquela organização.

Ao adquirir ou desenvolver um sistema de informação, as organizações esperam trazer eficiência e eficácia para seus processos e sua gestão. No caso das Secretarias de Assistência Social ambas podem ser traduzidas pela precisão das informações sobre os beneficiários de programas do governo, pela geração de relatórios obrigatórios ao alcance de um clique e na visualização, por meio de gráficos e tabelas, dos problemas sociais traduzidos em situações de vulnerabilidade e violação dos direitos básicos do cidadão. Nesse sentido, as características do GESUAS vão ao encontro do que se espera de um programa específico para a assistência social na visão de quem atua na área.

Outros aspectos importantes encontrados pela pesquisa são a morosidade do setor público e a capacitação de seus funcionários, que podem atuar como barreiras para a compra, implantação e uso de sistemas de informação. Além disso, a vontade política é um fator que deve ser ressaltado neste trabalho, dado que se constitui como uma relevante crítica para o cenário brasileiro. $O$ país não se encontra nas primeiras posições do ranking do Governo Eletrônico publicado pela ONU, evidenciando a necessidade em se investir e incentivar a informatização das instituições públicas para melhorar sua transparência e a qualidade dos serviços prestados.

Espera-se que o trabalho possa ser utilizado para pesquisas futuras sobre o uso de sistemas de informação nas Secretarias de Assistência Social, já que o mesmo é usado por aproximadamente trinta prefeituras. A utilização de TICs pela gestão pública é um tema relevante e merece uma atenção especial da academia. Cada vez mais os processos de gestão podem se tornar eficientes e buscar a excelência com a informatização dos processos. Vale lembrar que o Estado trabalha para o povo, logo os sistemas de informação e outras tecnologias podem ser utilizadas no sentido de ampliar a participação social nas decisões e planejamentos governamentais. Experiências que dão luz a esses elementos são importantes para trabalhos futuros irem além do que já se tem de sistematizado sobre a temática.

\section{DEVELOPMENT AND USE OF MANAGEMENT SOFTWARE IN PUBLIC COMPANIES FROM AN ORGANIZATIONAL, TECHNOLOGICAL AND HUMAN DIMENSION PERSPECTIVE}

\begin{abstract}
This research is about the use of information systems in public administration, specifically in the Department of Social Services, where the software GESUAS was developed to assist in their management. To reach the proposed objectives, the program developer and staff of the Department of Social Service in Viçosa, in Minas Gerais state, were interviewed. The collected data was treated via content analysis. After the interviews, analytical categories were created to study the impact of GESUAS on that organization. It was noted that the use of the system has positive implications in the organizational, as well as in the technological and human aspects. Based on these findings, it is possible to note the importance of using technology and information systems in organizations, although the results obtained here cannot be generalized to other cases.
\end{abstract}

Keywords: Information Technology. Information Systems. Public Administration.

\section{REFERÊNCIAS}

BARDIN, L. Análise de conteúdo. São Paulo: Edições 70, 1977.

BRASIL. Ministério do Desenvolvimento Social e Combate à Fome. Sistema Único de Assistência Social. Disponível em: <http://mds.gov.br/assuntos/assistencia-social/>. Acesso em: 30 set. 2015.

CAPELLA, Ana Cláudia Niedhardt. A política brasileira de governo eletrônico: um estudo sobre o "Portal Brasil". In: Encontro de Administração Pública e Governança da ANPAD, 4., 2010, Vitória. Anais... Rio de Janeiro: ANPAD, 2010 
GODOY, A. S. Introdução à pesquisa qualitativa e suas possibilidades. São Paulo: FGV, 1995.

LAUDON, K. C.; LAUDON, J. P. Sistemas de Informação Gerenciais. 9. ed. São Paulo: Pearson Prentice Hall, 2010.

LAURINDO, F. J. B. Tecnologia da Informação: planejamento e gestão de estratégias. São Paulo: Atlas, 2008.

LAURINDO, F. J. B. et al. O Papel da tecnologia da informação ( $\mathrm{TI})$ na estratégia das organizações. Revista Gestão \& Produção, São Carlos, v. 8, n. 2, p. 160-179, ago. 2001.

MATTOS, A. C. M. Sistemas de informação: uma visão executiva. São Paulo: Saraiva, 2005.

MEDEIROS, P. H. R; GUIMARÃES, T. A. O estágio do governo eletrônico no Brasil em relação ao contexto mundial. Revista do Serviço Público, Brasília, v. 55, n. 1, p. 49-66, 2004.

MELO, I. S. Administração de sistemas de informação. São Paulo: Pioneira, 2002.

MONTEIRO, B. R. P. et al. O Processo de implantação do sistema de informação de custos do Governo Federal do Brasil, Brasília/DF, 2011. Disponível em: <http://www3.tesouro.gov.br/Sistema_Informacao_ custos/downloads/PROCESSO_DE_IMPLANTACAO_DO_SIC.pdf>. Acesso em: 12 set. 2015.

O’BRIEN, J. A. Sistemas de informação e as decisões gerenciais na era da Internet. São Paulo: Saraiva, 2004.

ONU. United Nations. E-government survey 2014 ranking: e-government for the future we want. [2014]. Disponível em: <http://unpan3.un.org/egovkb/Portals/egovkb/Documents/un/2014-Survey/E-Gov_ Complete_Survey-2014.pdf>. Acesso em: 30 set. 2015.

SANTOS JÚNIOR, S; FREITAS, H; LUCIANO, E. M. Dificuldades para o uso da tecnologia da informação. São Paulo: ERA Eletrônica, 2005.

SILVA, A; RIBEIRO, J. A; RODRIGUES, L. A. Sistemas de informação na administração pública. Rio de Janeiro: Revan, 2004.

SIQUEIRA NETO, J. F; MENEZES, D. F. N. E-Gov - Estágio atual e perspectivas. Revista Direito Mackenzie, São Paulo, v. 6, n. 1, p. 144-149, 2013.

STAIR, R. M; REYNOLDS, G. W. Princípios de sistemas da informação: uma abordagem gerencial. São Paulo: Pioneira Thomson Learning, 2006.

VERGARA, S. C. Métodos de pesquisa em administração. São Paulo: Atlas, 2005.

YIN, R. K. Estudo de caso: planejamento e métodos. 4. ed. Porto Alegre: Bookman, 2010. 